\title{
Aportes
}

\section{Las dificultades de las matemáticas}

\author{
José Germán Hoyos Salazar \\ Decano Facultad de Ingeniería Mecánica, Universi- \\ dad Autónoma de Manizales.
}

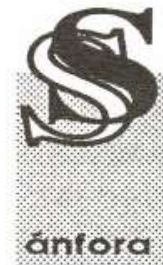

i preguntamos a un estudiante del bachillerato, cuál asignatura le parece más difícil, su respuesta será, sin duda, el curso de matemáticas. Algunos factores influyen en el fenómeno y en este artículo trataré de analizarlos someramente:

La primera dificultad sería la falta de medios auxiliares.

Deteniéndonos en su aspecto más externo, vemos que las Matemáticas carecen de estos elementos que facilitan la enseñanza de otras asignaturas. La geografía, por ejemplo, casi tanto como en los libros, la aprendemos en mapas, gráficas y películas culturales que nos dan a conocer las regiones y costumbres de los pueblos más apartados de nosotros. Si pasamos a la literatura, no cabe duda que el contacto directo con las obras de los grandes autores y las lecturas de párrafos selectos, al mismo tiempo que nos revela sus cualidades, despierta en nosotros un vivo interés.

Los experimentos de física y química, las clases prácticas y visitas a museos en las asignaturas de ciencias naturales, las láminas y dibujos, son ejemplos que podrían multiplicarse referente a las otras materias. Junto a estos valiosos auxiliares, no admiten comparación esas modestas figuras geométricas de cartón o madera que constituyen el único, casi exclusivo, material pedagógico de Ias Matemáticas.
Una segunda dificultad que podemos mencionar es la íntima relación de las partes. Vemos, que en la misma exposición de la materia, ya el profesor de Matemáticas se encuentra en desventaja. Y si sólo fuera esto. Porque en el momento de iniciar sus clases, la buena voluntad tropieza con un obstáculo: las deficiencias de los estudiantes en conocimientos anteriores, indispensables, como base sólida, para construir el edificio matemático corrrespondiente al curso. En geografía, por ejemplo, puede un estudiante aprender muy bien las cordilleras de América, sin necesidad de conocer los ríos de Europa, estudiados, digamos en clases anteriores. En anatomía, no se necesita tener presente el número de huesos del cuerpo humano, para realizar una brillante exposición del aparato nervioso. En historia, aun cuando no 
se recuerden las hazañas de Napoleón, no resulta imposible comprender el por qué de la invasión Alemana a Francia en la segunda guerra mundial. Lo mismo podríamos decir de otras asignaturas, aunque claro está, un conocimiento de sus diversas partes ayudaría a encontrar la explicación de ciertos hechos, por ejemplo, la economía de un país en sus relaciones con los recursos naturales, topografía, vías de comunicación, desarrollo social y cultural. Pero nunca esta relación se presenta tan necesaria como en las Matemáticas.

En ellas se hace constante alusión a los teoremas y aplicaciones expuestos no sólo en clases anteriores sino lo ya explicado en anteriores oportunidades. $\mathrm{Al}$ alumno que no comprende los principios del álgebra, la trigonometría le parecerá una pesadilla. Y cómo profundizar en álgebra, si pasó a través de la aritmética sin aprender bien sus teorías y aplicaciones, incluso sin seguridad en las operaciones con los quebrados?

Las matemáticas constituyen una asignatura en la que cada nuevo paso presupone un perfecto conocimiento de los anteriores, sin los cuales, los avances son sólo aparentes, se construye en terreno movedizo y ante la primera dificultad el edificio se desmorona.

\section{A lo anterior podemos sumar ciertos prejuicios.} Creo que el de mayor importancia es el estado sicológico del alumno cuando inicia estos estudios. Por diversas circunstancias, existe un ambiente lleno de prejuicios acerca de las matemáticas. El estudiante incapaz de reaccionar ante ellos, se encuentra ya en un cierto estado de ánimo poco favorable. Cuántas veces hemos oído : «es una asignatura muy difícil»...»aún, a los que les va bien en las otras materias, en ésta tienen notas bajas»... «Yopienso estudiar para Abogado y para nada necesitaré las Matemáticas...» Y así, insensiblemente, capitulan muchos estudiantes, aceptando una triste derrota sin esforzarse en ganar la batalla!.

Cuán distinto hubiera sido el resultado de haber vivido en sus espíritus el noble aliciente de «pueden, porque se creen fuertes». Pero ese aliciente exige un esfuerzo continuo que no siempre todos los estudiantes están dispuestos a realizar. Las Matemáticas no son de esas asignaturas cuyo examen se improvisa en los últimos días del curso, gracias a una buena memoria o a una gran facilidad de inventiva. Y este esfuerzo metódico y cotidiano, necesario para triunfar al final, acobarda a no pocos estudiantes.

Favorece también esta tendencia hacia el mínimo esfuerzo, el ambiente que rodea al estudiante en su vida ordinaria. Nuestra época se caracteriza por ese inmoderado afán que se introduce, con diversas modalidades, en todas nuestras acciones. Queremos los triunfos fáciles y a corto plazo, es decir, la «ley del menor esfuerzo». Y claro está que esta vida moderna, tan agitada, dificulta en gran parte el hábito de la tranquila y reposała reflexión y la inclinación a un raciocinio sereno. Los estudiantes viven la mayor parte del tiempo fuera de sí y por eso resulta tan difícil concentrarse y pensar por sí mismo.

Supongamos que el estudiante en sus primeros años de bachillerato posea una adecuada base matemática y se sienta interesado por esta asignatura. Pronto, al iniciar el estudio, por ejemplo, del álgebra, tropezará con un obstáculo casi insuperable para algunos en los primeros meses del curso: su carácter abstracto. El paso de los números a las letras, las operaciones con expresiones algebraicas, la incógnita $x$ de las ecuaciones, en una palabra, la generalización de fórmulas y reglas que se presenta a sus mentes juveniles como un difícil enigma que deben descifrar. Existe cosa más absurda, al menos a primera vista, que razo- 
nar con números «irracionales» ?, o representar gráficamente los números «imaginarios» ?

Si a esta no pequeña dificultad, adicionamos la falta de preparación pedagógica y la ausencia de método y orden que a veces encuentran en sus profesores, bien se comprende que ellos no sean tan culpables de sus amargas desilusiones y fracasos.

Reconocidas las anteriores dificultades y otras más que podrían adicionarse, con todo, tal vez no se haya atribuido su debida importancia a otro factor que explica, al menos en parte, el origen de muchas de ellas: los alumnos no saben estudiar matemáticas. No todas las asignaturas se estudian del mismo modo, y precisamente en esto estriba un aspecto del valor formativo peculiar de cada una de ellas. Unas se dirigen preferentemente a la imaginación, otras al sentimiento; unas desarrollan memoria o el espíritu de observación, otras el razonamiento y el estudio de las relaciones y causas. Si el estudiante aplica el mismo método a todos sus estudios, comprueba que a pesar de su continuo esfuerzo los resultados obtenidos son muy diversos en unas y otras asignaturas. Entonces, es natural que se sienta atraído hacia aquellas en las que triunfa y experimente una aversión hacia las restantes, entre las que se encuentran, casi invariablemente, las Matemáticas.

El comprender el problema, aceptando su existencia y no desanimándose ante las dificultades que presenta es, normalmente, el primer paso para resolverlo.

Indudablemente, existen especiales dificultades en la enseñanza de las Matemáticas. Corresponde, pues, a los profesores de estaasignatura disminuirlas en cuanto sea posible. Cómo?. Haciendo cuanto de ellos dependa.

El profesor que vive el sentimiento de su noble misión educativa, no dejará de encontrar mil ingeniosos procedimientos para hacer sus clases amenas e interesantes, se preocupará por los adelantos de la moderna pedagogía, hallará valiosos argumentos para motivar a sus estudiantes; sin caer en excesos, les hará ver la utilidad de las matemáticas en sus posibles futuras carreras y profesiones y su importancia en la vida moderna y sabrá aprovechar en beneficio de sus alumnos, los recursos educativos y formativos que las matemáticas poseen.

En resumen, sin pretender que «todos» sus alumnos resulten excelentes matemáticos y sobresalgan en esta asignatura, sí conseguirá eliminar paulatinamente muchos prejuicios, despertar en ellos la afición a las matemáticas y descubrir y orientar los talentos matemáticos de su clase.

Los estudiantes, por su parte, comprenderán que no siempre es justo atribuir a otros factores extrínsecos la causa de sus débiles progresos, y que para adelantar en esta asignatura es preciso entregarse a su estudio desde los primeros años. Si en lugar de considerar a las matemáticas como una materia árida, difícil, misteriosa, ven en ellas un instrumento para la formación integral de su personalidad, y en sus dificultades un objetivo digno de poner a prueba sus energías y capacidad intelectual, pronto experimentarán esa íntima alegría que acompaña a toda empresa ardua, iniciada en el cumplimiento del deber y coronada por cl triunfo.

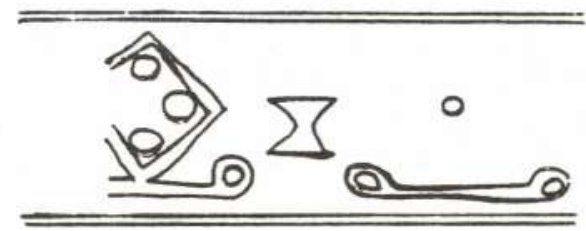

